\title{
ESTÁGIO SUPERVISIONADO: um relato de experiências
}

Guilherme Francisco Silva

Graduando em Geografia - Universidade Federal de Uberlândia guilhermegeo59@gmail.com

\section{Introdução}

A profissão docente, antes de mais nada, é o ato de amar e se dedicar no processo de formação pessoal e acadêmica do próximo. De antemão já podemos afirmar que esta não é uma tarefa fácil, pois exige muita competência de quem se dispõe a realizar esta profissão, porém quando o objetivo desta é alcançado a sensação de dever cumprido é imensa. A docência significa se dispor ao próximo de forma integral com o intuito de direcionar o ensino laico, de forma que o objetivo não seja a transformação do próximo e sim auxilio ao sujeito na sua formação pessoal e acadêmica para que este seja capaz de influir de forma crítica as suas decisões no espaço socialmente construído.

Neste sentido tonar-se imprescindível a função do estágio supervisionado na formação acadêmica dos futuros docentes, sendo este o momento propício para o contato e a vivência cotidiana com o ambiente escolar. Certamente este também é o momento em que dúvidas foram esclarecidas e que outras indagações surgiram ao decorrer do mesmo.

Dentro deste contexto o estágio supervisionado se faz de grande valia para que possamos distinguir diferentes realidades e que a partir do momento em que essas elucidadas podemos nos adequar e escolher os melhores métodos e as melhores metodologias de ensino.

O objetivo deste trabalho é relatar as experiências vividas durante os quatros semestres dedicados ao estágio supervisionado. Iniciando pelo Estágio Supervisionado 1 (voltado para desenvolvimento de atividades relacionados a Educação Infantil e anos iniciais do Ensino Fundamental); o Estágio Supervisionado 2 (dedicado aos anos finais do Ensino Fundamental - $6^{\circ}$ ano ao $9^{\circ}$ ano); passando pelo Estágio Supervisionado 3 (inserção no Ensino Médio e na Educação de Jovens e Adultos - EJA) e finalizando com as experiências no Estágio Supervisionado 4 (com a assimilação dos desafios e práticas do ensino no campo).

Num sentido empírico o estágio supervisionado é junção dos conhecimentos teóricos e práticos desenvolvidos até o presente momento na trajetória acadêmica, mesmo sabendo que estes na maioria das vezes caminham em direções opostas. Portanto o estágio não pode ser analisado ao mero reducionismo de ser somente uma atividade prática e teórica. Devemos considerar a presença desconexa de vários saberes disciplinares que não condizem com a 
realidade do âmbito profissional e superá-los de forma que estes não dificultem o processo de ensino-aprendizagem do maior patrimônio de um docente: seus alunos.

\section{Estágio Supervisionado 1: a experiência no ensino infantil e nos anos iniciais do ensino fundamental}

O percurso das nossas experiências no Estágio Supervisionado (ESPV) teve como ponto de partida o Ensino Infantil (EI). A Lei $n^{\circ}$ 9.394, de 20 de dezembro de 1996 (LBD) estruturou o EI de modo que caberia ao Estado garantir de forma gratuita o ensino das crianças de 0 a 5 anos de idade. Essa inclusão constituiu um ganho, sem precedentes, na história da Educação Infantil em nosso país e marcou o início da democratização do ensino público e gratuito no país, a partir da Constituição Federal de 1988.

Alinhado a este marco legislatório o Ministério da Educação e Desporto, atualmente Ministério da Educação e Cultura (MEC) lançou luz a Política Nacional de Educação Infantil em 1994 e que foi revisada no ano de 2012. Segundo esta o ensino da criança até 5 (cinco) anos de idade tem por objetivo o desenvolvimento integral da mesma, em seus aspectos físico, afetivo, psicológico, intelectual e social, complementando a ação da família e da comunidade.

Pois bem após esta contextualização a primeira etapa do Estágio Supervisionado 1 (ESPV 1) se deu a partir das reflexões e argumentações sobre o Ensino Infantil e Fundamental I, através da exposição de aulas, leituras e discussões de textos, que norteiam os parâmetros curriculares nacionais da educação. O conhecimento prático se fez presente a partir de uma visita orientada numa escola de educação infantil (EMEI - Marta Helena) e na vivência prática na Escola Estadual Orlanda Neves Strack, ambas localizadas no município de Uberlândia - MG.

A escola visitada foi o EMEI (Escola Municipal de Educação Infantil) Marta Helena, localizada na rua Bahia, nº 2319, no bairro Marta Helena, zona norte de Uberlândia. A mesma foi criada a mais de 25 anos com a função de servir como creche, posteriormente a mesma adquiriu a função de escola infantil. O EMEI Marta Helena disponibiliza 117 vagas (todas ocupadas) em período integral, atendendo uma faixa etária de 04 meses aos 03 anos.

A metodologia aplicada na escola segue os parâmetros da Política Nacional de Educação Infantil de 2006 em paridade com as diretrizes estaduais e municipais para educação em consonância com a Lei n ${ }^{\circ} 11.444 / 13$, que instituiu a Rede Pública Municipal pelo Direito de Ensinar e de Aprender, na Lei Federal $n^{\circ} 10.639 / 03$ e lei $n^{\circ} 11.645 / 08$ 
Infelizmente não tive contato com o Projeto Político Pedagógico (PPP), pois no dia 2 da visita, a diretora e nem a supervisora estavam presentes.

Nota-se o uso frequente da linguagem fílmica como metodologia de ensino do alfabeto e de objetos. A arte também é usada como metodologia para compreensão e distinção de cores. O uso de brinquedos também é muito utilizado, mas com uma função de entreter os alunos e não uma função metodológica. Todas as salas são dispostas de forma que os alunos tenham a liberdade de andar, deitar e brincar com total segurança e conforto. Não poderia ser diferente, pois o estímulo ao ato de brincar é prioridade na EI, pois estimula a sociabilidade dos alunos e o conhecimento do mundo.

Quanto ao estágio no Ensino Fundamental I, este foi realizado na Escola Municipal Professora Orlanda Neves Strack, localizada na rua Da Produção, bairro Minas Gerais, setor norte. A mesma constitui-se em uma instituição de Ensino Fundamental, que atende cerca de 820 alunos do $1^{\circ}$ ano ao $9^{\circ}$ ano nos períodos manhã e tarde. A maioria dos alunos atendidos pela escola (cerca de 90\%) são moradores do bairro supracitado.

Conforme estabelecido pelo plano de estágio, o desenvolvimento do mesmo se deu a partir do reconhecimento da estrutura interna e externa da escola; análise dos livros didáticos utilizados pela escola; participação nos eventos escolares; análises das documentações oficiais da instituição (Projeto Político Pedagógico - PPP). Esta segunda etapa do estágio propiciou uma primeira experiência com o ambiente escolar, servindo como base para os estágios seguintes.

\section{Estágio supervisionado 2: anos finais do ensino fundamental}

O objetivo do Estágio Supervisionado 2 (ESPV 2) é proporcionar aos futuros professores um contato mais amplo com o seu campo de trabalho a partir do conhecimento de diretrizes teóricas-metodológicas que balizam o processo de ensino-aprendizagem do ensino fundamental $2\left(6^{\circ}\right.$ ao $9^{\circ}$ ano). Este foi realizado na mesma instituição do ESPV I, a Escola Municipal Professora Orlanda Neves Strack.

Efetivamente o ESPV 2 representou o primeiro contato direto com alunos, pois o mesmo proporcionou que as regências fossem realizadas. Durante o período do estágio foram realizadas atividades que permitiram reflexões sobre o cotidiano escolar, além de documentos oficiais que permeiam as atividades desenvolvidas durante o magistério. Dentre essas atividades merece destaque a análise do Projeto Político Pedagógico da instituição, a 
elaboração de planos de aula, a prática regente em anos diferenciados do ensino fundamental 2, a participação em projetos desenvolvidos na escola entre outros. Se faz de grande valia o ES2 pois esse se traduz na melhor ferramenta de introdução do aluno graduando em licenciatura no cotidiano do magistério.

Além das atividades propostas para o estágio na instituição de ensino, foram elaboradas outras voltadas para a formação docente. Dentre elas destaca-se a participação no "I Simpósio Regional de Geografia e Interdisciplinaridade Escolar: Potencialidades e Inclusões" foi realizado pelo Laboratório de Geografia e Educação Popular (LAGEPOP) - IG/ UFU, nos dias 17, 18 e 19 de novembro de 2016.no campus UFU - Santa Mônica. O objetivo do mesmo era promover a troca de experiências e práticas entre alunos da Universidade Federal de Uberlândia e Professores da Educação Básica, propondo a divulgação e reflexão sobre o processo de ensino-aprendizagem nas escolas, em todas as realidades existentes.

Outro evento de grande destaque e que contribui de forma expressiva "Escola Sem Partido e o ensino da Geografia - PET Geografia e o movimento de ocupação na escola secundarista".

O evento Escola Sem Partido e o ensino da Geografia: paradoxos e desafios foi realizado no dia 17 de outubro de 2016 pelo PET Geografia onde estiveram presentes para compor a mesa os professores: Dr. Sérgio Luiz Miranda (Instituto de Geografia - IG/UFU), Wesley Ribeiro (E. E. Segismundo Pereira) e Maurício Aquilante Policarpo (Programa de extensão e ensino Ações Formativas Integradas - AFIN/UFU).

Este evento foi realizado num momento em que a educação pública neste país foi acometida por série de ataques antidemocráticos por parte dos governantes. Todo sistema público está sob alvo de reformas que procuram desestimular o pensamento crítico de professores e alunos. O principal argumento utilizado por eles, é que os professores influenciam os alunos. Desta forma colocam os alunos como a parte mais vulnerável todo processo de ensino aprendizagem.

Destaca-se neste processo o movimento de ocupação das escolas públicas por parte dos alunos secundaristas, reivindicando o direito de aprender e a livre docência de seus professores. O movimento começou nas grandes metrópoles e se espalhou pelas cidades do interior do país, ganhando o apoio inclusive de alguns pais e diretores de escola. Foi um ato de nobre de resistência, contra a política de um governo que não tem o respaldo da população e que tem como premissa um neoliberalismo perverso. 


\section{Estágio supervisionado 3: experiências no ensino médio e educação de jovens e adultos}

Esta terceira fase do estágio consistiu em vivenciar o Ensino Médio e a Educação de Jovens e Adultos (EJA). O estágio foi realizado na escola Estadual Hortêncio Diniz (EEHD) localizada na cidade de Uberlândia, no Bairro Marta Helena, na rua Alexandrino Garcia, número 387. A escola foi criada em 1968 e desde lá atende os alunos do Ensino Fundamental I e II, Ensino Médio e EJA, funcionando nos turnos diurno, vespertino e noturno, atendendo alunos do Bairro Marta Helena e bairros da região vizinha.

O Estágio Supervisionado 3 (ESPV 3) permitiu o contato com alunos que estudam no período noturno que possuem uma realidade totalmente diferente dos outros. A maioria destes trabalham ou exercem outras atividades que são conciliadas com os estudos.

Este estágio foi importante pelo de fato de proporcionar aos alunos a discussão sobre temas bastantes atuais como: a Reforma do Ensino Médio (Lei n $\left.{ }^{\circ} 13.415 / 2017\right)$. Foi possível promover uma roda de conversa com os alunos do Ensino Médio noturno e esclarecer algumas dúvidas.

A Lei 13415/2017 reformula o atual ensino de geografia causando um desmonte a educação pública brasileira além de limitar a formação discente e emancipação do mesmo como indivíduo livre e pensante. O aluno deve sair do Ensino Médio apto a compreender as relações entre sociedade e natureza que permeiam seu cotidiano. Conflitos, lutas e dinâmicas, sejam elas de ordem ambiental ou socioeconômica devem estar evidentes aos alunos. Retirar o ensino de geografia das escolas é uma afronta as tantas conquistas travadas para se conseguir uma geografia minimamente crítica e capaz de olhar para além das linhas postas na sociedade contemporânea.

Contraditória talvez seja uma das principais palavras ao problematizar tal reforma. Elementos como o "notório saber", isto é, aprovação de professores sem formação na licenciatura fere as Diretrizes Curriculares Nacionais (DCN), pois esta tem como objetivo a Formação Inicial e Continuada dos Profissionais do Magistério da Educação Básica e ações que visam a valorização da carreira docente. $\mathrm{O}$ ensino de geografia como já foi mencionado será amplamente prejudicado. Os alunos perderão conteúdos referentes principalmente a criticidade geográfica típica dos anos finais do Ensino Médio, elemento este que continuará a ser cobrado em ENEM e vestibulares intensificando assim o acesso de alunos de escola 
pública no ensino superior em detrimento das amplas possibilidades dos alunos do ensino privado.

\section{Estágio supervisionado 4: educação no campo}

A educação no campo (EC) constitui-se numa modalidade de ensino voltado para população rural, regimentada pela Lei de Diretrizes e Bases para Educação Nacional (LDB) nas disposições gerais. $\mathrm{O}$ artigo 28 desta lei rege sobre a adequação do ensino na zona rural de modo que as necessidades locais sejam atendidas.

Na oferta de educação básica para a população rural, os sistemas de ensino promoverão as adaptações necessárias à sua adequação às peculiaridades da vida rural e de cada região, especialmente: conteúdos curriculares e metodologias apropriadas às reais necessidades e interesses dos alunos da zona rural; organização escolar própria, incluindo adequação do calendário escolar às fases do ciclo agrícola e às condições climáticas; adequação à natureza do trabalho na zona rural. (BRASIL, 1996).

Além da regulamentação da EC através da LDB, o Ministério da Educação e Cultura (MEC) lançou em 2013 o Programa Nacional de Educação do Campo (PRONACAMPO) que visa organizar políticas que atendam às necessidades da EC e quilombola.

Diante deste cenário a proposta do Estágio Supervisionado 4 (ESPV 4) foi proporcionar aos estagiários o contato com um possível ambiente de trabalho. Para tanto o mesmo foi realizado na Escola Municipal do Moreno, localizado na comunidade Tenda do Moreno, no município de Uberlândia.

O estágio consistiu em 40 horas/aulas práticas que envolveram atividades de regência; de observação de aulas e participações em eventos da escola. A instituição de ensino atende um público de aproximadamente 200 alunos de diferentes realidades.

Dentre as atividades que merecem ênfase quanto ao ESPV 4 é o caminho percorrido pelos alunos na ida e volta da escola. Muitos desses despertam por volta de 5:00 e 6:00 horas da manhã para conseguir chegar na escola. O caminho até a escola percorre vários desafios como a poeira, a chuva, o cansaço físico que assolam a maioria dos alunos. O horário de funcionamento da escola é só turno vespertino, contemplando desde da Educação Infantil até Ensino Fundamental 2.

Destarte, o ESPV 4 representou uma grande oportunidade de contato com um ambiente de trabalho, que na maioria das vezes é ignorada pelos cursos de formação docente e pelas 
políticas públicas relacionadas ao ensino. Foi possível perceber a dedicação dos profissionais envolvidos no processo de ensino aprendizagem dos alunos. Um destaque negativo é a grande evasão de alunos, muito em função dos filhos de trabalhadores rurais que atuam no regime de temporário.

\section{Considerações Finais}

O estágio como ferramenta de introdução de licenciados ao seu campo de trabalho se mostra de grande valia, pelo fato de proporcionar o conhecimento teórico e prático da estrutura escolar, das políticas públicas que regem o ensino, assim como a experiência como docente. Cada etapa do estágio tem relevante importância.

O ESPV 1, inicia uma caminhada de quatro disciplinas, nas quais o aluno terá contato mais direto com seu campo de trabalho após a formação inicial. A experiência no ensino infantil e nos anos iniciais do fundamental permite aos estagiários perceber todo processo de ensino aprendizagem que os alunos passam até chegar aos anos finais do ensino fundamental, que por acaso, é o primeiro campo de atuação do licenciado em Geografia.

O conteúdo teórico proposto para esta disciplina ESPV 2 contribuirá com a preparação do estagiário para o desenvolvimento de suas atividades nos anos finais do ensino fundamental. Nessa etapa os estagiários tiveram a oportunidade de ter acesso às discussões propostas, bem como ao material didático pertinente, a fim de pensar rumos para a sua prática docente.

O ESPV 3 constitui uma importante disciplina na cadeia de estágios cursados pelos alunos do curso de Licenciatura em Geografia. Nesta fase os estagiários tiveram a oportunidade de ingressar na realidade do Ensino Médio. O contato com alunos de uma faixa etária mais avançada, num período de grandes incertezas, proporciona aos estagiários uma vivência ímpar na sua formação como docente.

Por fim, o ESPV 4 proporciona um contato com uma realidade totalmente diferente para a maioria dos estagiários. O ensino no campo com todos os seus desafios não pode ser renegado por nós futuros docentes.

\section{Referências}


BRASIL. Ministério da Educação. Secretaria de Educação Básica. Política Nacional de Educação Infantil: pelo direito das crianças de zero a seis anos à educação. Brasília: MEC, SEB, 2006.32 p. Disponível em:

<http://portal.mec.gov.br/seb/arquivos/pdf/pol_inf_eduinf.pdf >. Acesso em 28 nov. 2017.

Lei $\mathrm{n}^{\circ}$ 9.394, de 20 de dezembro de 1996. Estabelece as diretrizes e bases da educação nacional. Diário Oficial [da] República Federativa do Brasil, Brasília, DF, 23 dez. 1996.Disponível em: <https://www.planalto.gov.br/ccivil_03/Leis/L9394.htm>. Acesso em: 09 out. 2016.

Lei $\mathrm{n}^{\circ} 10.639$, de 9 de janeiro de 2003. Altera a Lei $\mathrm{n}^{\mathrm{o}}$ 9.394, de 20 de dezembro de 1996, que estabelece as diretrizes e bases da educação nacional, para incluir no currículo oficial da Rede de Ensino a obrigatoriedade da temática "História e Cultura Afro-Brasileira", e dá outras providências. Diário Oficial [da] República Federativa do Brasil, Brasília, DF, 12 jan.2003. Disponível em: <http://www.planalto.gov.br/ccivil_03/leis/2003/L10.639.htm>. Acesso em: 09 out. 2016.

Lei $\mathrm{n}^{\circ} 11.645$, de 10 de março de 2008. Altera a Lei $\mathrm{n}^{\mathrm{0}}$ 9.394, de 20 de dezembro de 1996, modificada pela Lei n⿳0 10.639 , de 9 de janeiro de 2003, que estabelece as diretrizes e bases da educação nacional, para incluir no currículo oficial da rede de ensino a obrigatoriedade da temática "História e Cultura Afro-Brasileira e Indígena". Diário Oficial [da] República Federativa do Brasil, Brasília, DF, 12 mar. 2008. Disponível em:<http://www.planalto.gov.br/ccivil_03/_ato2007-2010/2008/lei/111645.htm>. Acesso em: 09 out. 2016.

. Lei $\mathrm{n}^{\circ} 13.415$, de 16 de fevereiro de 2017. Altera as Leis $\mathrm{n}^{\mathrm{os}}$ 9.394, de 20 de dezembro de 1996, que estabelece as diretrizes e bases da educação nacional, e 11.494, de 20 de junho 2007, que regulamenta o Fundo de Manutenção e Desenvolvimento da Educação Básica e de Valorização dos Profissionais da Educação, a Consolidação das Leis do Trabalho - CLT, aprovada pelo Decreto-Lei $n^{-0} 5.452$, de $1^{\underline{0}}$ de maio de 1943 , e o Decreto-Lei $\mathrm{n}^{0}$ 236, de 28 de fevereiro de 1967; revoga a Lei $\mathrm{n}^{\mathrm{0}}$ 11.161, de 5 de agosto de 2005; e institui a Política de Fomento à Implementação de Escolas de Ensino Médio em Tempo Integral. Diário Oficial [da] República Federativa do Brasil, Brasília, DF. Disponível em: < http://www.planalto.gov.br/ccivil_03/_ato2015-2018/2017/lei/L13415.htm>. Acesso em 20 nov.2017.

Programa Nacional de Educação no Campo. Diário Oficial [da] República

Federativa do Brasil. Ministério da Educação. Brasília, DF, 2013.Disponível em: $<$ http://portal.mec.gov.br/index.php?option=com_docman\&view=download\&alias $=132$ 14-documento-orientador-do-pronacampo-pdf\&Itemid=30192>. Acesso em: 20 nov.2017.

UBERLÂNDIA. Lei no 11.444 , de 24 julho de 2013. Institui a rede pública municipal pelo direito de ensinar e de aprender no município de Uberlândia e dá outras providências. Diário Oficial [da] Prefeitura de Uberlândia. Disponível em:< https://leismunicipais.com.br/a1/mg/u/uberlandia/lei-ordinaria/2013/1145/11444/lei-ordinarian-11444-2013-institui-a-rede-publica-municipal-pelo-direito-de-ensinar-e-de-aprender-nomunicipio-de-uberlandia-e-da-outras-providencias?q=11444>. Acesso em: 28 nov. 2016. 